\title{
Thermal stability of oxide-supported gold nanoparticles
}

\author{
Nazila Masoud $^{1} \cdot$ Tomas Partsch $^{1} \cdot$ Krijn P. de Jong $^{1} \cdot$ Petra E. de Jongh ${ }^{1}$
}

Received: 28 August 2018 / Accepted: 23 April 2019 /Published online: 16 May 2019

(C) The Author(s) 2019

\begin{abstract}
In this study, we report on the influence of support and gas atmosphere on the thermal stability of Au nanoparticles on oxidic supports. All samples were prepared with a modified impregnation method and have initial Au particle sizes in the range of $3-$ $4 \mathrm{~nm}$. We observed that in air, Au nanoparticles on $\mathrm{SiO}_{2}$ and $\mathrm{Al}_{2} \mathrm{O}_{3}$ are thermally much more stable than Au nanoparticles on $\mathrm{TiO}_{2}$. For instance, upon treatment up to $700{ }^{\circ} \mathrm{C}$, on $\mathrm{SiO}_{2}$, Au particles grew from 4 to $6 \mathrm{~nm}$ while on $\mathrm{TiO}_{2}$ from 3 to $13 \mathrm{~nm}$. For $\mathrm{Au}$ nanoparticles on $\mathrm{TiO}_{2}$, growth is accelerated by oxidizing atmospheres and the presence of water and/or chloride. On nonreducible supports and in non-oxidizing atmosphere, the supported Au nanoparticles were remarkably stable. The insight into the growth of oxide-supported Au nanoparticles in reactive atmosphere offers an additional tool for a rational choice of a support for high-temperature gas-phase reactions involving gold nanocatalysts.
\end{abstract}

Keywords $\mathrm{Au} \cdot$ Sintering $\cdot$ Support effect $\cdot$ Atmosphere effect

\section{Introduction}

By development of environmental protection regulations, less $\mathrm{CO}$ emission is demanded. Most of the $\mathrm{CO}$ emission occurs when the engine is still cold [1]. Gold is the most active catalyst for $\mathrm{CO}$ oxidation at room temperature which makes $\mathrm{Au}$ catalysts very interesting for this application [2-6]. However, when the engine becomes hot, it reaches the temperatures as high as $700{ }^{\circ} \mathrm{C}$, and high-temperature treatment often causes growth of Au nanoparticles [7-14]. For bulk Au, the melting point is $1064^{\circ} \mathrm{C}$, and the Hüttig temperature at which surface atoms become mobile is $319{ }^{\circ} \mathrm{C}$. For Au nanoparticles, the melting point is even lower [15]. Hence, one can expect the growth of $\mathrm{Au}$ nanoparticles at elevated temperatures. Deactivation due to particle growth is irreversible and detrimental to the long-term activity of the catalyst. Different stateof-the-art strategies [16-19] have been employed to combat the particle growth. For instance, a high thermal stability of

Electronic supplementary material The online version of this article (https://doi.org/10.1007/s13404-019-00259-9) contains supplementary material, which is available to authorized users.

Petra E. de Jongh

p.e.dejongh@uu.nl

1 Inorganic Chemistry and Catalysis, Debye Institute for Nanomaterials Science, Utrecht University, 3584 CG Utrecht, the Netherlands
Au nanoparticles on combinatory $\mathrm{TiO}_{2} / \mathrm{SiO}_{2}$ support [20], hydroxyapatite $/ \mathrm{TiO}_{2}$ support [21], nanorods of $\mathrm{TiO}_{2}$ [22], and perovskite support [23] has been reported.

Supports stabilize Au nanoparticles by enhancing interparticle spacing and sometimes by metal support interaction $[24,25]$. For instance, Au nanoparticles on $\mathrm{Al}_{2} \mathrm{O}_{3}$ have shown excellent stability upon treatment at $650{ }^{\circ} \mathrm{C}$ under oxidizing conditions $[2,26,27]$. However, $\mathrm{Au} / \mathrm{TiO}_{2}$ catalyst, which is the most studied type of Au catalyst, is known to grow during $\mathrm{CO}$ oxidation [28-30] as well as during high-temperature treatment under oxidizing atmosphere [7], though the exact conditions that cause the growth are under discussion [29, 30]. $\mathrm{Au} / \mathrm{TiO}_{2}$ catalysts are known to deteriorate during storage, as they are light and moisture sensitive [31, 32]. The stability of $\mathrm{Au} / \mathrm{SiO}_{2}$ is under debate [33-40]. Though there are some examples of stability and/or instability of supported Au nanoparticles, the influence of the nature of the support and reaction conditions on the stability is not well understood.

More importantly, the mechanisms that are involved in Au particle growth under different conditions are unclear. Particle growth can take place via two major mechanisms [41]. The first one involves nanoparticle diffusion over the support surface and coalescence to form larger particles (particle diffusion and coalescence). The diffusion is more likely for smaller particles, and it is accelerated when the temperature increases, roughly following Arrhenius behavior [42]. Near the Tamman temperature, at which the metal atoms acquire sufficient energy for their bulk mobility, particle diffusion becomes more dominant. 
Secondly, larger particles grow at the expense of smaller particles (Ostwald ripening) [11, 41]. The driving force is that the higher surface energy of low coordinated metal atoms at the surface of small particles destabilizes the small particles and makes the larger particles, compared with smaller particles, energetically more favorable. Hence, metal species detach from small particles, diffuse over the support or through the vapor phase, and can attach to larger particles with a lower chemical potential. This leads to the growth of larger particles at the expense of smaller particles.

According to fundamental studies by Wynblatt and Gjostein [42], Ostwald ripening can have two possible ratelimiting steps: detachment of metal atom from small particles in form of mobile species, the so-called interface-controlled regime, and diffusion of mobile species from smaller particles to the larger one, the so-called diffusion-controlled regime. Mobile species can be metal atoms or metal ions of metalcontaining molecules. In the latter, the metal or metal ions are complexed and stabilized by surface groups and/or species from the gas phase that act as ligands. Ligands decrease the activation energy for the detachment of a metal (ion) from a nanoparticle. Hence, the formation of mobile species depends on the presence of reactive gases, certain surface groups, and/ or oxidizing or reducing conditions [25]. For example, fast growth of $\mathrm{Pt} / \mathrm{Al}_{2} \mathrm{O}_{3}$ under $\mathrm{O}_{2}$ atmosphere was attributed to the formation of volatile $\mathrm{PtO}_{2}$ species under oxidizing atmosphere as well as a high diffusivity of $\mathrm{PtO}_{2}$ over the support surface [43]. The growth of Ni nanoparticles during the methanation reaction was ascribed to the formation of gasphase $\mathrm{Ni}(\mathrm{CO})_{5}$ as mobile species [44]. The most likely mobile species in different reactive conditions can be predicted by calculating thermodynamics and energy barriers for the diffusion of the different possible complexes. For instance, based on DFT calculations, $\mathrm{CuCO}$ species were assumed to be the mobile species in $\mathrm{Cu} / \mathrm{ZnO}$ catalysts under methanol synthesis conditions and during water gas shift reaction [45].

To the best of our knowledge, there is no systematic study on the growth of Au nanoparticles on different supports that are prepared with the same method and have similar composition, support porosity, and initial Au particle size. Catalyst preparation method affects the stability of supported nanoparticles by influencing catalyst properties such as distribution of Au particles over the support and the concentration of contaminants like $\mathrm{Cl}$ that can promote particle growth [46]. A uniform spatial distribution of particles, with maximum interparticle distances of supported nanoparticles, and a very narrow particle size distribution play an important role in minimizing particle growth $[44,47]$.

In this study, we report on the growth of Au nanoparticles on supports with different properties using non-reducible ones $\left(\mathrm{SiO}_{2}\right.$ and $\gamma$-alumina) and a reducible one $\left(\mathrm{TiO}_{2}\right)$. We employed a modified incipient wetness impregnation method to prepare 3 to $4 \mathrm{~nm} \mathrm{Au}$ nanoparticles on $\mathrm{TiO}_{2}, \mathrm{Al}_{2} \mathrm{O}_{3}$, and
$\mathrm{SiO}_{2}$ supports [48]. The effect of different reactive gases on the particle growth was investigated. The activation energies of particle growth for Au on different supports and in different reactive gases were experimentally obtained as well.

\section{Experimental}

\section{Sample preparation}

Commercially available supports, $\mathrm{TiO}_{2}$ (rutile, $\mathrm{BET}$ surface area of $30 \mathrm{~m}^{2} \mathrm{~g}^{-1}$, pore volume of $0.12 \mathrm{~mL} \mathrm{~g}^{-1}$, SigmaAldrich), $\mathrm{SiO}_{2}$ (Aerosil, BET surface area of $50 \mathrm{~m}^{2} \mathrm{~g}^{-1}$, pore volume of $0.12 \mathrm{~mL} \mathrm{~g}^{-1}$, Evonik), and $\mathrm{Al}_{2} \mathrm{O}_{3}$ (gamma phase, BET surface area of $120 \mathrm{~m}^{2} \mathrm{~g}^{-1}$, pore volume of $0.46 \mathrm{~mL} \mathrm{~g}^{-1}$, Alfa-Aesar) were used. Not the most commonly used P25, $\mathrm{TiO}_{2}$ with mixed phases of anatase and rutile, but instead pure rutile was used because at $500{ }^{\circ} \mathrm{C}$ and above, anatase phase transforms to rutile phase [49], and this change in support phase could contribute to particle growth.

Gold was deposited on the supports by a modified incipient wetness impregnation method developed by Delannoy et al. [48]. In a typical preparation, the support $(1 \mathrm{~g})$ was dried under vacuum at $200{ }^{\circ} \mathrm{C}$ and was impregnated with an aqueous $\mathrm{Au}$ solution (appropriate concentration of $\mathrm{HAuCl}_{4} \cdot 3 \mathrm{H}_{2} \mathrm{O}$, SigmaAldrich) to prepare $1 \mathrm{wt} \% \mathrm{Au}$ on $\mathrm{TiO}_{2}$ and $\mathrm{SiO}_{2}$ and $4 \mathrm{wt} \%$ $\mathrm{Au}$ on $\mathrm{Al}_{2} \mathrm{O}_{3}$. The sample was aged at room temperature under vacuum for $1 \mathrm{~h}$ and then washed twice with ammonia solution $(30 \mathrm{~mL}$ each time, $1 \mathrm{M})$ to remove $\mathrm{Cl}$ and twice with water $(30 \mathrm{~mL}$ each time) at RT. Each time, the solid was recovered by centrifugation. The $\mathrm{Au} / \mathrm{SiO}_{2}$ sample was washed with diluted ammonia solution at lower $\mathrm{pH}(\mathrm{pH}=8)$ to remove $\mathrm{Cl}$ and to avoid dissolution of $\mathrm{SiO}_{2}$ as well. The sample was then dried under vacuum at room temperature for $48 \mathrm{~h}$ or was dried in a freeze drier at $-20{ }^{\circ} \mathrm{C}$ under 0.1 mbar vacuum for $17 \mathrm{~h}$. The dried samples were further treated in air $\left(100 \mathrm{~mL} \mathrm{~min}^{-1}\right.$ ) from RT to $300{ }^{\circ} \mathrm{C}\left(\operatorname{ramp~} 2{ }^{\circ} \mathrm{C} \mathrm{min}^{-1}\right)$ and kept at $300{ }^{\circ} \mathrm{C}$ for $4 \mathrm{~h}$ before cooling down and stored in a desiccator in the dark.

Another sample of $\mathrm{Au} / \mathrm{TiO}_{2}$ was prepared with the method of deposition-precipitation with urea [46] to promote preparation of a Cl-free sample. In a typical preparation, the support $(1 \mathrm{~g}$, rutile, Sigma-Aldrich) was dispersed in water $(100 \mathrm{~mL})$ in a $500-\mathrm{mL}$ polyethylene bottle, and the reaction mixture was stabilized in an oil bath at $80{ }^{\circ} \mathrm{C}$. An aqueous Au solution ( $2 \mathrm{~mL}, 0.027 \mathrm{M}, \mathrm{HAuCl}_{4} \cdot 3 \mathrm{H}_{2} \mathrm{O}$ precursor, Sigma-Aldrich) and urea $(300 \mathrm{mg})$ were added. The reaction mixture was stirred for $16 \mathrm{~h}$ in a closed container at $80{ }^{\circ} \mathrm{C}$ in the dark. Then, the solid was recovered by centrifugation and was washed eight times with water ( $40 \mathrm{~mL}$ each time) at RT. The sample was then dried in a freeze drier at $-20^{\circ} \mathrm{C}$ under $0.1 \mathrm{mbar}$ vacuum for $17 \mathrm{~h}$. The dried samples were further reduced in $\mathrm{H}_{2}\left(100 \mathrm{~mL} \mathrm{~min}{ }^{-1}\right.$ ) from $\mathrm{RT}$ to $300{ }^{\circ} \mathrm{C}$ (ramp 
$2{ }^{\circ} \mathrm{C} \min ^{-1}$ ) and kept at $300{ }^{\circ} \mathrm{C}$ for $2 \mathrm{~h}$ before cooling down and stored in a desiccator in the dark.

\section{Characterization}

Elemental analysis was performed on an inductively coupled plasma-mass spectrometer (Mikroanalytisches Laboratorium Kolbe, Germany) after destruction of the samples at high temperature and pressure. Chloride content of the samples was determined by ion chromatography (Mikroanalytisches Laboratorium Kolbe). Transmission electron microscopy (TEM) imaging was performed on a Tecnai 12 (FEI) microscope operated at $120 \mathrm{kV}$. Particle sizes were determined from the micrographs as $\sum n_{i} d_{i} \sum n_{i}$, where $d_{i}$ is the diameter of typically 200-300 individual particles on different areas of the sample. High-angle annular dark-field scanning transmission electron microscopy (HAADF-STEM) was performed on a Talos F200X microscope operated at $200 \mathrm{kV}$. STEM image processing was carried out using Tecnai Imaging Analysis (TIA).

\section{Thermal treatment}

The thermal treatment of the samples was performed either under static condition or in a gas flow. The experiments under static condition were performed in a temperature-calibrated muffle furnace. Typically, $40 \mathrm{mg}$ of the sample was heated in air from RT to 500,600 , or $700{ }^{\circ} \mathrm{C}\left(\operatorname{ramp~} 5{ }^{\circ} \mathrm{C} \min ^{-1}\right)$ and kept at the specified temperature for $4 \mathrm{~h}$. The experiments in flows of different gases, compressed air (wet air), synthetic air (dry air), $\mathrm{H}_{2}, \mathrm{~N}_{2}$, or $\mathrm{N}_{2}$ that was bubbled through water at RT (100 $\left.\mathrm{mL} \mathrm{min}^{-1}\right)$, were performed on $200 \mathrm{mg}$ of the sample in a plug flow reactor with diameter of $2 \mathrm{~cm}$ at $500{ }^{\circ} \mathrm{C}$ with the same heating program. The experiments in flow of $\mathrm{H}_{2}$ at 600 and $700{ }^{\circ} \mathrm{C}$ were done in a crucible with a horizontal tubular furnace under the flow of $25 \mathrm{~mL} \mathrm{~min}{ }^{-1}$ to imitate the static condition in air. The experiments and analytical measurements were performed at least twice to ensure reproducibility of the results.

Activation energy of particle growth was calculated from the Arrhenius plots (In (particle growth rate) versus 1/T), where particle growth rate is estimated from the changes in particle sizes upon $4 \mathrm{~h}$ of thermal treatment at different temperatures $(T)$.

\section{Results}

\section{Sample characteristics}

Figure 1 shows transmission electron micrographs of $\mathrm{Au}$ nanoparticles supported on three different supports. Particle sizes for these prepared samples were between 2.5 and
$4.0 \mathrm{~nm}$ (Table 1). Determination of particle sizes relied on TEM micrographs, as crystallite sizes could not be derived from X-ray diffraction patterns owing to low Au loading and overlap of diffraction patterns. With bright-field TEM, particle sizes were difficult to determine for the $\mathrm{Au} / \mathrm{TiO}_{2}$ sample due to a low contrast. Therefore, in this case, additional high-angle annular dark-field scanning transmission electron microscopy (HAADF-STEM) was employed. HAADF-STEM micrographs (Figure S.1) showed particle size of $2.6 \pm 0.6 \mathrm{~nm}$ for the $\mathrm{Au} / \mathrm{TiO}_{2}$ which confirms the accuracy of the particle size obtained by bright-field TEM.

Table 1 presents the structural properties of the samples. The Au loading for each sample was chosen based on the BET surface areas of the corresponding supports aiming for similar inter-particle distances for all samples. For instance, the surface area of the commercially available $\gamma-\mathrm{Al}_{2} \mathrm{O}_{3}$ is four times higher than that of $\mathrm{TiO}_{2}$; hence, a four times higher Au loading for the $\mathrm{Au} / \mathrm{Al}_{2} \mathrm{O}_{3}$ was targeted. The average inter-particle distances were between 30 and $50 \mathrm{~nm}$ for all the supported $\mathrm{Au}$ nanoparticles. Elemental analysis showed that targeted $\mathrm{Au}$ loadings were achieved and the $\mathrm{Cl}$ content of all samples is between 0.3 and $0.4 \mathrm{wt} \%$. For comparison, an $\mathrm{Au} / \mathrm{TiO}_{2}$ sample with negligible $\mathrm{Cl}$ content was prepared by the method of deposition-precipitation with urea. Hence, all the supported Au samples had similar properties, though the as-prepared Au nanoparticles on $\mathrm{TiO}_{2}$ had slightly smaller sizes than the two other samples.

\section{Impact of the support on the thermal stability}

Figure 2 shows TEM micrographs of the $\mathrm{Au} / \mathrm{TiO}_{2}$ sample upon treatment to temperatures up $700{ }^{\circ} \mathrm{C}$ in air. Additionally, Figure S.2 shows the ones for $\mathrm{Au} / \mathrm{SiO}_{2}$ and $\mathrm{Au} / \mathrm{Al}_{2} \mathrm{O}_{3}$. These figures demonstrated that all supported $\mathrm{Au}$ nanoparticles have grown upon thermal treatment. However, growth for $\mathrm{Au}$ nanoparticles on $\mathrm{TiO}_{2}$ was more pronounced (Fig. 2).

Figure 3 shows, in summary, the evolution of particle size distributions and shows that the particles grew with increasing temperature. The particles for the $\mathrm{Au} / \mathrm{TiO}_{2}$ sample were initially smaller than those for the $\mathrm{Au} / \mathrm{SiO}_{2}$ and $\mathrm{Au} / \mathrm{Al}_{2} \mathrm{O}_{3}$ samples, but they grew more upon thermal treatments: 2.1-fold increase in diameter at $500{ }^{\circ} \mathrm{C}, 2.4$-fold at $600{ }^{\circ} \mathrm{C}$, and 5.0 fold at $700{ }^{\circ} \mathrm{C}$. Furthermore, the particle size distribution was broadening. The $\mathrm{Au}$ nanoparticles on $\mathrm{SiO}_{2}$ and $\mathrm{Al}_{2} \mathrm{O}_{3}$ grew too, but to a limited extent: for the $\mathrm{Au} / \mathrm{SiO}_{2}$ : no significant growth at $500{ }^{\circ} \mathrm{C}, 1.1$-fold at $600{ }^{\circ} \mathrm{C}$, and 1.8 -fold at $700{ }^{\circ} \mathrm{C}$. The particle size for the $\mathrm{Au} / \mathrm{TiO}_{2}$-DPU that contained no $\mathrm{Cl}$ increased too: 1.7 -fold at $500{ }^{\circ} \mathrm{C}, 2.4$-fold at $600{ }^{\circ} \mathrm{C}$, and 4.3 fold at $700{ }^{\circ} \mathrm{C}$. This particle growth was less than for the $\mathrm{Au} /$ $\mathrm{TiO}_{2}$ with some $\mathrm{Cl}$, in agreement with the literature that suggests $\mathrm{Cl}$ residue enhances growth of Au nanoparticles on $\mathrm{TiO}_{2}$ [50]. Nevertheless, $\mathrm{Au}$ nanoparticles on $\mathrm{TiO}_{2}$, even with 
Fig. 1 Transmission electron micrographs for the $0.9 \mathrm{wt} \% \mathrm{Au} /$ $\mathrm{TiO}_{2}$ (a), $1.0 \mathrm{wt} \% \mathrm{Au} / \mathrm{SiO}_{2}(\mathbf{b})$, and $4.0 \mathrm{wt} \% \mathrm{Au} / \mathrm{Al}_{2} \mathrm{O}_{3}$ (c)

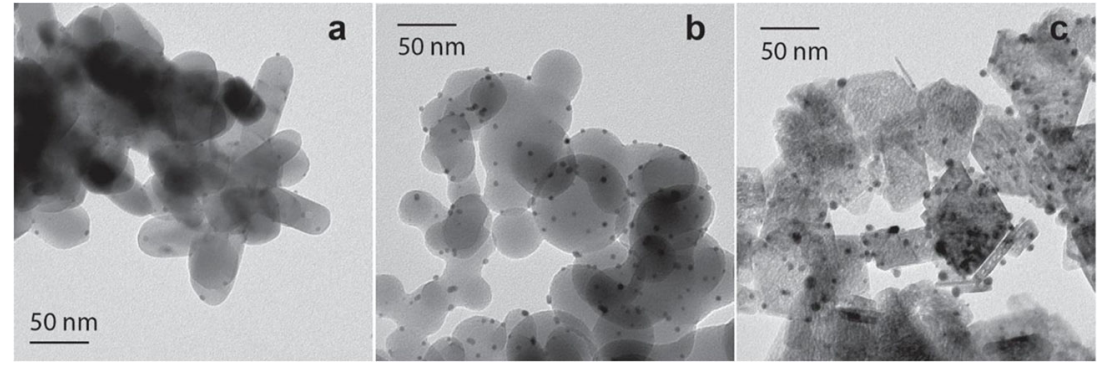

negligible $\mathrm{Cl}$ content, were thermally less stable than the ones on $\mathrm{SiO}_{2}$ and $\mathrm{Al}_{2} \mathrm{O}_{3}$ in air.

\section{Effect of atmosphere}

Figure 4 compares the thermal stability of Au nanoparticles on $\mathrm{TiO}_{2}$ and $\mathrm{SiO}_{2}$ under different atmospheres, varying from reducing (a flow of $\mathrm{H}_{2}$ ) via inert (a flow of $\mathrm{N}_{2}$ ) towards oxidizing (a flow of wet air). First, for the $\mathrm{Au} / \mathrm{TiO}_{2}$, the particle growth was negligible in either $\mathrm{H}_{2}$ or $\mathrm{N}_{2}$, but it became more pronounced in the presence of water vapor ( $\sim 2 \mathrm{~mol} \%$ water in $\mathrm{N}_{2}, 1.6$-fold increase) and in the presence of dry air (3.1-fold increase). It means that presence of $\mathrm{O}_{2}$ and/or water accelerated the thermal growth of Au nanoparticles on $\mathrm{TiO}_{2}$ supports. In contrast, no significant difference in particle growth, and in both cases a high thermal stability, was observed either in inert atmosphere or in the presence of $\mathrm{H}_{2}$. This observation excluded strong metal support interaction between $\mathrm{Au}$ and the reducible $\mathrm{TiO}_{2}$ support, which typically occurs under reducing conditions, as a reason for the high stability of Au nanoparticles on $\mathrm{TiO}_{2}$ in the flow of $\mathrm{H}_{2}$. Hence, the particle growth occurred for the $\mathrm{Au} / \mathrm{TiO}_{2}$ only in the presence of $\mathrm{O}_{2}$ and/or water.

In contrast, Fig. 4 shows that for the $\mathrm{Au} / \mathrm{SiO}_{2}$, the particle growth was negligible under all atmospheres tested. In summary, the growth of Au nanoparticles was influenced by the atmosphere only when they were supported on the $\mathrm{TiO}_{2}$, but not when they were supported on $\mathrm{SiO}_{2}$, and particle growth was more pronounced in an oxidizing atmosphere.

Figure 5 shows the Arrhenius plots for rates of Au nanoparticles growth $(\mathrm{d} R / \mathrm{d} t$, where $R$ is the particle diameter and $t$ is time) on the $\mathrm{TiO}_{2}$ and $\mathrm{SiO}_{2}$ under different atmospheres. The $\mathrm{d} R / \mathrm{d} t$ was extracted from plots in Figure S.3. The activation energies of particle growth $\left(E_{\mathrm{a}}\right)$ estimated from the plots are given in Fig. 5 as well. In air, $E_{\mathrm{a}}$ for $\mathrm{Au} / \mathrm{TiO}_{2}(36 \pm$ $\left.10 \mathrm{~kJ} \mathrm{~mol}^{-1}\right)$ was lower than the one for $\mathrm{Au} / \mathrm{SiO}_{2}(86 \pm$ $14 \mathrm{~kJ} \mathrm{~mol}^{-1}$ ). However, in $\mathrm{H}_{2}$, the $E_{\mathrm{a}}$ was similar for $\mathrm{Au}$ nanoparticles on both $\mathrm{TiO}_{2}$ and $\mathrm{SiO}_{2}(80 \pm 6$ vs $81 \pm$ $13 \mathrm{~kJ} \mathrm{~mol}^{-1}$ ). Notably, $E_{\mathrm{a}}$ for the $\mathrm{Au} / \mathrm{SiO}_{2}$ under different atmospheres was also similar. This suggests that the ratelimiting step in particle growth for the $\mathrm{Au} / \mathrm{TiO}$ and $\mathrm{Au} / \mathrm{SiO}_{2}$ in $\mathrm{H}_{2}$ and for the $\mathrm{Au} / \mathrm{SiO}_{2}$ in air might be similar whereas rate of $\mathrm{Au}$ nanoparticle growth on $\mathrm{TiO}_{2}$ is apparently not or much less limited by this step in air. This will be discussed in more detail in the "Discussion" section.

\section{Discussion}

There are a few reports on the growth of Au nanoparticles supported on $\mathrm{TiO}_{2}$ upon high-temperature treatment and under oxidizing atmosphere [7]. Akita et al. reported that $\mathrm{Au}$ nanoparticles of $2.1 \mathrm{~nm}$ on $\mathrm{TiO}_{2}$ grew to $9.7-\mathrm{nm}$ particles upon calcination in air at $600{ }^{\circ} \mathrm{C}$ for $4 \mathrm{~h}$ [32]. A high thermal stability of $\mathrm{Au}$ nanoparticles on $\mathrm{Al}_{2} \mathrm{O}_{3}$ upon treatment at $650{ }^{\circ} \mathrm{C}$ in three-way catalysis conditions $[2,27]$ and in a flow of $\mathrm{O}_{2}$ [26] was previously reported. There is no consensus on the thermal stability of $\mathrm{Au}$ nanoparticles on $\mathrm{SiO}_{2}$. Some reports suggested that they grow [33-38]. For instance, Bore et al. [37] showed that Au nanoparticles of around $1 \mathrm{~nm}$ on mesoporous $\mathrm{SiO}_{2}$ grew to in average $6 \mathrm{~nm}$ upon $\mathrm{H}_{2}$ exposure
Table 1 Structural properties of the samples

\begin{tabular}{lclll}
\hline & BET surface area $\left(\mathrm{m}^{2} \mathrm{~g}^{-1}\right)$ & Au loading $(\mathrm{wt} \%)$ & $\mathrm{Cl}$ content (wt\%) & Particle size (nm) \\
\hline $\mathrm{Au} / \mathrm{TiO}_{2}$ & 30 & 0.9 & 0.4 & $2.7 \pm 1.2$ \\
$\mathrm{Au} / \mathrm{TiO}_{2}-\mathrm{DPU}^{\mathrm{a}}$ & 30 & 1.0 & $<100 \mathrm{ppb}^{\mathrm{b}}$ & $2.3 \pm 0.6$ \\
$\mathrm{Au} / \mathrm{SiO}_{2}$ & 50 & 1.0 & 0.4 & $3.6 \pm 0.9$ \\
$\mathrm{Au} / \mathrm{Al}_{2} \mathrm{O}_{3}$ & 120 & 4.0 & 0.3 & $3.8 \pm 1.3$ \\
\hline
\end{tabular}

${ }^{\text {a }}$ Sample was prepared by deposition-precipitation with urea. All other samples were prepared by modified incipient wetness impregnation

${ }^{\mathrm{b}}$ Below the detection limit 
Fig. 2 Transmission electron micrographs of $0.9 \mathrm{wt} \% \mathrm{Au} / \mathrm{TiO}_{2}$ that has been treated, from left to right, upon treatment at 500,600, and $700^{\circ} \mathrm{C}$ in static air for $4 \mathrm{~h}$

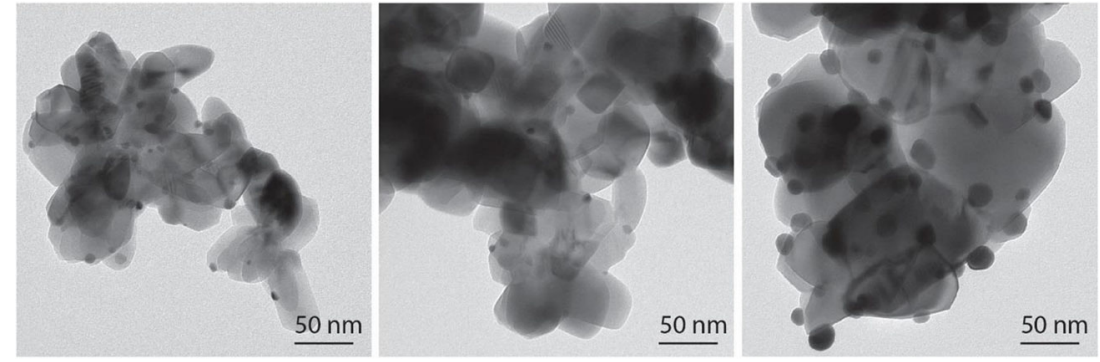

at $200{ }^{\circ} \mathrm{C}$. In contrast, some other reports claimed that if the $\mathrm{Au} / \mathrm{SiO}_{2}$ contains little or no $\mathrm{Cl}$, the $\mathrm{Au}$ nanoparticles are actually stable upon $\mathrm{O}_{2}$ exposure at $500{ }^{\circ} \mathrm{C}[39,40]$. In the latter case, the high stability of $\mathrm{Au}$ nanoparticles on $\mathrm{SiO}_{2}$ was attributed to a strong bond between $\mathrm{Au}$ and defects on the surface of $\mathrm{SiO}_{2}$. It was proposed that the defects on the surface were made during deposition of $\mathrm{Au}$ on the $\mathrm{SiO}_{2}$ by magnetron sputtering [40]. Barret et al. showed as well that enhanced defect sites on the $\mathrm{TiO}_{2}$ surface make the supported Au nanoparticles thermally stable [22]. All mentioned reports are examples obtained under catalysis conditions on powder catalysts. On 2D model systems in vacuum, the interaction of $\mathrm{Au}$ with reducible supports like $\mathrm{TiO}_{2}$ is suggested to provide stable $\mathrm{Au}$ nanoparticles [28, 51]. Accordingly, $\mathrm{Au}$ on nonreducible $\mathrm{Al}_{2} \mathrm{O}_{3}$ and $\mathrm{SiO}_{2}$ supports is suggested to be less stable [16]. Our study clearly proves a higher thermal stability of $\mathrm{Au}$ nanoparticles on the non-reducible supports $\mathrm{SiO}_{2}$ and $\mathrm{Al}_{2} \mathrm{O}_{3}$ than on $\mathrm{TiO}_{2}$.

It is known that gas atmosphere can affect the growth of metal nanoparticles. Oxidizing atmospheres typically induce faster rates of particle growth than reducing atmospheres [43, 52]. Particularly for $\mathrm{Au} / \mathrm{TiO}_{2}$, it was reported that $\mathrm{Au}$ particle sizes are smaller if the sample is prepared in $\mathrm{H}_{2}$ or $\mathrm{Ar}$ than when it is prepared in $\mathrm{O}_{2}$ [31]. However, to the best of our knowledge, this is the first report that shows that the situation is different for different supports and that the $\mathrm{Au}$, regardless of the atmosphere, is thermally stable on the $\mathrm{SiO}_{2}$ support.

This is also the first time that the activation energies of particle growth under conditions closer to catalytic reaction conditions for $\mathrm{Au}$ on different supports and in different reactive gases are obtained. For comparison, the activation energy of particle growth for Ni nanoparticle catalysts under steam reforming condition was estimated to be $46 \pm 8 \mathrm{~kJ} \mathrm{~mol}^{-1}$ [53]. The activation energy of particle growth for Au particles supported on single-crystal $\mathrm{TiO}_{2}$ (110) under ultra-high vacuum was estimated as high as $280 \mathrm{~kJ} \mathrm{~mol}^{-1}[54,55]$. Notably, this higher value was obtained under UHV conditions rather than relevant catalytic conditions and on atomically flat clean surfaces rather than powder supports with surface groups and adsorbed molecules [54]. Hence, one can conclude that under conditions closer to the catalytic reaction conditions, the activation energy of particle growth is much lower and often particle growth is much faster than for $2 \mathrm{D}$ model systems in vacuum.

As mentioned in the "Introduction" section, particle growth can take place via two mechanisms: particle diffusion and coalescence or Ostwald ripening. Our results suggest three main conclusions on involved particle growth mechanisms: First, particle diffusion and coalescence as a major particle growth mechanism is unlikely. The distance between the particles is estimated to be around $50 \mathrm{~nm}$ for all the samples. Our previous reports on the growth of $\mathrm{Cu}$ nanoparticles during methanol synthesis showed a very strong dependence of particle diffusion and coalescence on inter-particle size with diffusion dominating at such large distances unlikely $[47,56]$. Furthermore, DFT calculations showed that Au nanoparticles interact much stronger with $\mathrm{TiO}_{2}$ surfaces than with $\mathrm{SiO}_{2}$ surfaces [40]. If high-temperature treatments do not induce particle diffusion and coalescence for the $\mathrm{Au}$ nanoparticles on $\mathrm{SiO}_{2}$, it is unlikely that particle diffusion and coalescence take place for the $\mathrm{TiO}_{2}$ surfaces under similar conditions. Therefore, particle growth by Ostwald ripening most likely is the main particle growth mechanism at least under oxidizing atmospheres. It has been suggested that particle growth by Ostwald ripening is also the main growth mechanism for the Au on single-crystal $\mathrm{TiO}_{2}$ (110) under ultra-high vacuum upon a high-temperature treatment [28].

Identifying the mobile species is not trivial [57]. Because of the large influence of the chemical nature of the support on particle growth observed in this study, a second conclusion would be that the mobile species are at the support surface rather than in gas phase. At temperatures of $177^{\circ} \mathrm{C}$ and above, $\mathrm{Au}$ does not form any stable oxides [58] or volatile compounds like $\mathrm{Pt}$ does in the form of $\mathrm{PtO}_{2}$. The energy required to remove a metal atom from a metal particle is high, close to the heat of sublimation of metals [53], which is $368 \mathrm{~kJ} \mathrm{~mol}^{-1}$ for $\mathrm{Au}[54,55]$. The fact that the experimentally observed $E_{\mathrm{a}}$ for growth of Au nanoparticles are an order of magnitude lower leads to a third conclusion that Au is unlikely to detach from a nanoparticle in metallic form. Furthermore, using the Kelvin equation, saturation pressures for $\mathrm{Au}$ nanoparticles with different sizes at different temperatures were calculated (supporting information, estimation of the diffusion of atomic $\mathrm{Au}$ in the gas phase at different temperatures). From the 
Fig. 3 Evolution of particle size distributions and log normal fits for the as-prepared $\mathrm{Au}$ on $\mathrm{TiO}_{2}$, $\mathrm{SiO}_{2}$, and $\mathrm{Al}_{2} \mathrm{O}_{3}$ as well as for the samples that have been treated at 500,600 , and $700{ }^{\circ} \mathrm{C}$ in static air for $4 \mathrm{~h}$

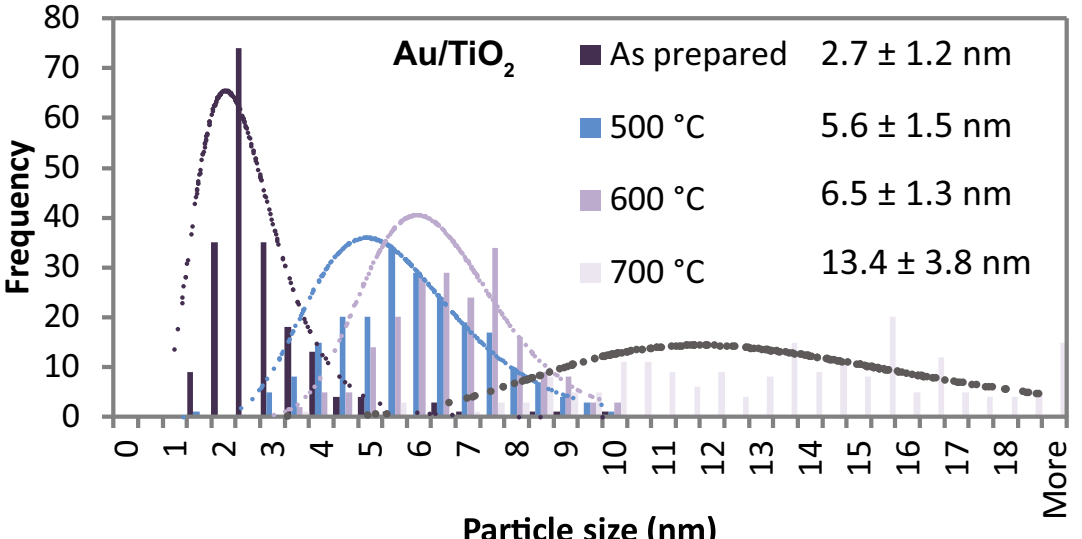

Particle size (nm)
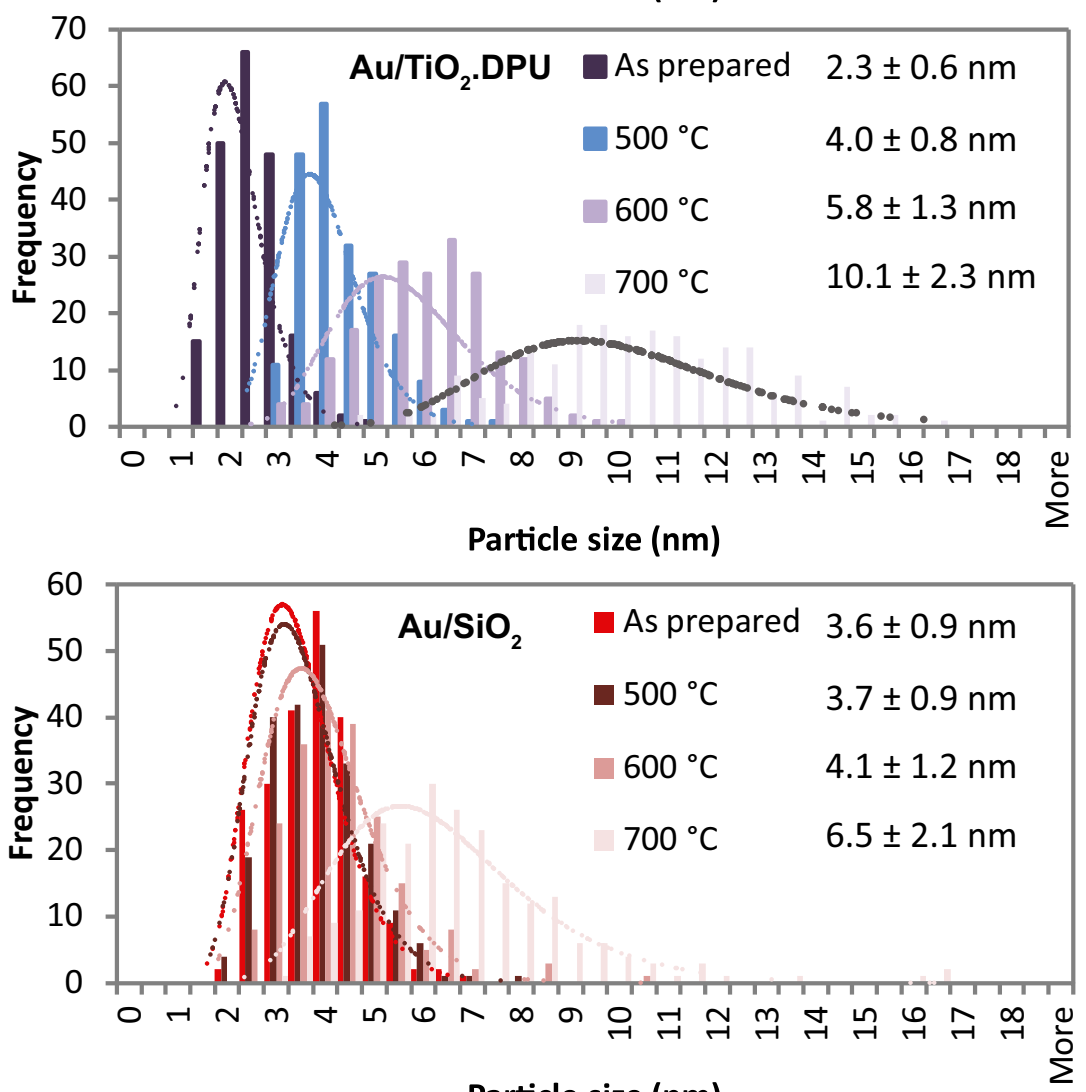

Particle size (nm)

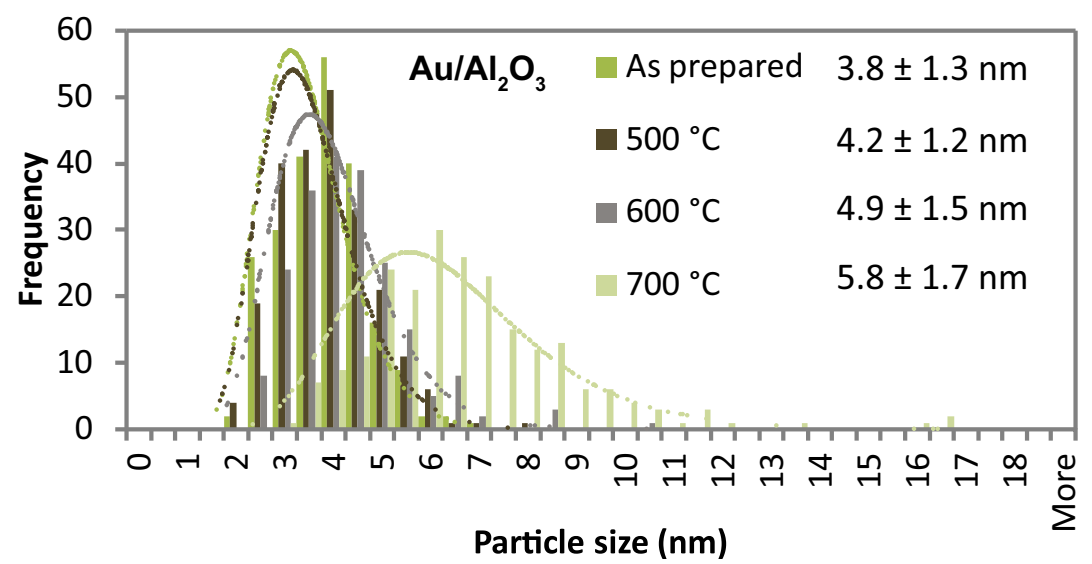




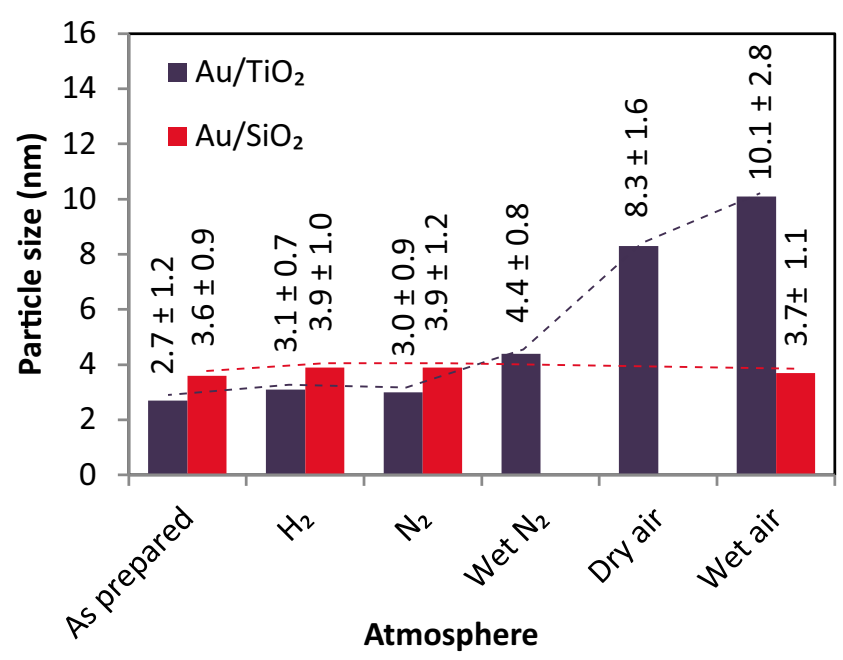

Fig. 4 Effect of gas composition on the size of Au nanoparticles on $\mathrm{TiO}_{2}$ or $\mathrm{SiO}_{2}$ that have been treated at $500{ }^{\circ} \mathrm{C}$ in different flows of gases $\left(100 \mathrm{~mL} \mathrm{~min}^{-1}\right)$ for $4 \mathrm{~h}$

difference in the saturation pressures of the Au vapor around the small and large Au nanoparticles, the diffusion rate for atomic $\mathrm{Au}$ in the gas phase was estimated. The calculation showed that Ostwald ripening via the atomic $\mathrm{Au}$ in the gas phase is not a main factor in explaining the observed particle growth. The observation that the formation and/or diffusivity of mobile species is accelerated on $\mathrm{TiO}_{2}$ and under oxidizing atmosphere as well as in the presence of $\mathrm{Cl}^{-}$ions strongly suggests adsorbed complexed and oxidized $\mathrm{Au}$ species being the mobile species.

It is remarkable that the $E_{\mathrm{a}}$ for particle growth in air on $\mathrm{Au} / \mathrm{TiO}_{2}$ is smaller than that on $\mathrm{Au} / \mathrm{SiO}_{2}$. This means that the formation and/or the diffusivity of the Au-complex mobile species is less favorable on $\mathrm{SiO}_{2}$. It is known, for instance, from $\mathrm{CO}$ oxidation studies [59-69], that $\mathrm{Au}$ and $\mathrm{TiO}_{2}$ have a very specific interaction, which leads to very active and possibly cationic gold species at the interface between the two, which might also play a role in diminishing the thermal stability of the $\mathrm{TiO}_{2}$-supported particles. It is remarkable that the $E_{\mathrm{a}}$ under other conditions, whether on $\mathrm{SiO}_{2}$ in either reducing or oxidizing conditions, or on $\mathrm{TiO}_{2}$ under reducing conditions, are all similar and in the range of $80-86 \mathrm{~kJ} / \mathrm{mol}$. This suggests that in the absence of this specific $\mathrm{Au}-\mathrm{TiO}_{2}$ interaction in oxidizing atmosphere, particle growth follows a similar mechanism. Tentatively, we propose that under oxidizing conditions cationic $\mathrm{Au}$ species are mobile species that are stabilized on $\mathrm{TiO}_{2}$ to a larger extent that on $\mathrm{SiO}_{2}$ in line with the lower activation energy for growth on the former (Fig. 5). In any case, the fact that Au catalysts on nonreducible supports show such high thermal stability, even though they often show lower activities than on reducible supports like $\mathrm{TiO}_{2}$ [70], is a very relevant consideration for the potential application of Au nanoparticles in gasphase catalysis.

\section{Conclusion}

For the first time, the thermal growth of Au nanoparticles on different oxidic supports and under different reactive atmospheres was studied. Similar initial particle sizes, in the 2.5 4-nm range, allowed direct comparison for the different supports. All supported $\mathrm{Au}$ nanoparticles grew upon thermal treatment. Particle growth on $\mathrm{TiO}_{2}$ was much more pronounced than that on either $\mathrm{SiO}_{2}$ or $\mathrm{Al}_{2} \mathrm{O}_{3}$. Particle growth on $\mathrm{TiO}_{2}$ was particularly enhanced by an oxidizing atmosphere, the presence of water, and/or the presence of $\mathrm{Cl}^{-}$. Particle growth by Ostwald ripening involving cationic gold species complexed by ligands was the most likely dominating growth mechanism. On non-reducible supports and in nonoxidizing atmosphere, the supported Au nanoparticles were remarkably stable. These results provide a better understanding of the growth of supported Au nanoparticles, and tools for a rational choice of a support for high-temperature gas-phase reactions involving gold catalysts.
Fig. 5 The Arrhenius plots of the rates of $\mathrm{Au}$ nanoparticles growth on $\mathrm{TiO}_{2}$ and $\mathrm{SiO}_{2}$ in static air and in a flow of $\mathrm{H}_{2}\left(25 \mathrm{~mL} \mathrm{~min}^{-1}\right.$, in a tube furnace) after $4 \mathrm{~h} . R$ is particle size and $t$ is time
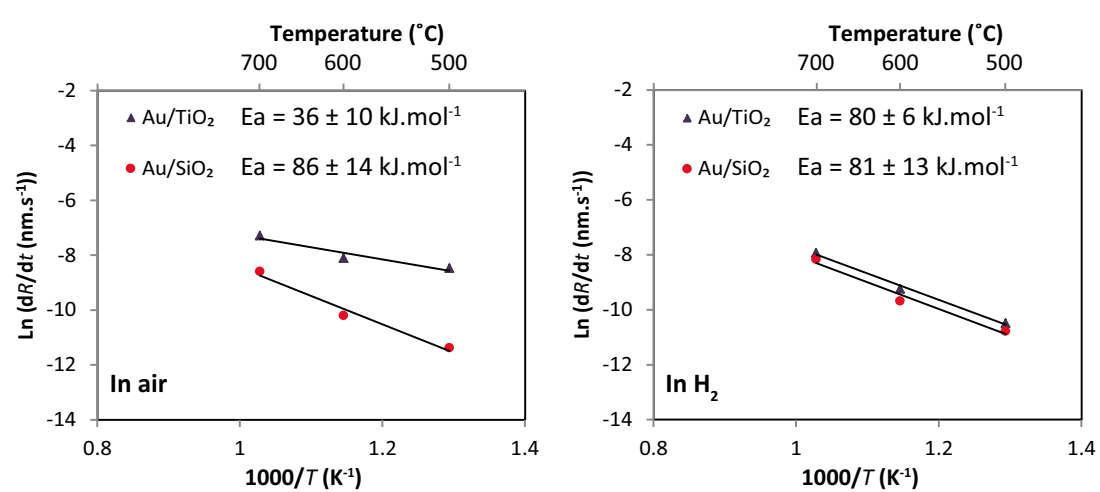
Acknowledgments We gratefully acknowledge Jessi van der Hoeven for the HAADF-STEM imaging and Neda Kordalivand from the Department of Pharmaceutical Sciences for operating the freeze drier.

Funding information This study received overall funding of the project from NWO-Vici (16.130.344). Krijn P. de Jong received support from the European Research Council, EU FP7 ERC Advanced Grant No. 338846.

\section{Compliance with ethical standards}

Conflict of interest The authors declare that there are no conflicts of interest.

Open Access This article is distributed under the terms of the Creative Commons Attribution 4.0 International License (http:// creativecommons.org/licenses/by/4.0/), which permits unrestricted use, distribution, and reproduction in any medium, provided you give appropriate credit to the original author(s) and the source, provide a link to the Creative Commons license, and indicate if changes were made.

\section{References}

1. Methods for monitoring and diagnosis the efficiency of catalytic converters: a patent-oriented survey (1998), vol 115. studies in surface science and catalysis. Elsevier. https://doi.org/10.1016/s01672991(98)80929-4

2. Ulrich V, Moroz B, Sinev I, Pyriaev P, Bukhtiyarov V, Grunert W (2017) Studies on three-way catalysis with supported gold catalysts. Influence of support and water content in feed. Appl Catal, B 203: 572-581. https://doi.org/10.1016/j.apcatb.2016.10.017

3. Bauer JC, Toops TJ, Oyola Y, Parks Ii JE, Dai S, Overbury SH (2014) Catalytic activity and thermal stability of $\mathrm{Au}-\mathrm{CuO} / \mathrm{SiO}_{2}$ catalysts for the low temperature oxidation of $\mathrm{CO}$ in the presence of propylene and NO. Catal Today 231:15-21. https://doi.org/10. 1016/j.cattod.2014.01.040

4. Haruta M (2014) Chance and necessity: my encounter with gold catalysts. Angew Chem Int Ed Engl 53(1):52-56. https://doi.org/ 10.1002/anie. 201305987

5. Min BK, Friend CM (2007) Heterogeneous gold-based catalysis for green chemistry: low-temperature $\mathrm{CO}$ oxidation and propene oxidation. Chem Rev 107(6):2709-2724. https://doi.org/10.1021/ cr050954d

6. Scurrell MS (2017) Thoughts on the use of gold-based catalysts in environmental protection catalysis. Gold Bull 50(1):77-84. https:// doi.org/10.1007/s13404-017-0194-z

7. Ma Z, Dai S (2014) Stabilizing gold nanoparticles by solid supports. In: Ma Z, Dai S (eds) Heterogeneous gold catalysts and catalysis. RSC, Stratford-upon-Avon, pp 1-26. https://doi.org/10. 1039/9781782621645-00001

8. Chen C, Nan C, Wang D, Su Q, Duan H, Liu X, Zhang L, Chu D, Song W, Peng Q, Li Y (2011) Mesoporous multicomponent nanocomposite colloidal spheres: ideal high-temperature stable model catalysts. Angew Chem Int Ed Engl 50(16):3725-3729. https:// doi.org/10.1002/anie.201007229

9. Wei Y, Zhao Z, Jin B, Yu X, Jiao J, Li K, Liu J (2015) Synthesis of AuPt alloy nanoparticles supported on 3D ordered macroporous oxide with enhanced catalytic performance for soot combustion. Catal Today 251:103-113. https://doi.org/10.1016/j.cattod.2014. 08.034

10. Laveille P, Guillois K, Tuel A, Petit C, Basset JM, Caps V (2016) Durable PROX catalyst based on gold nanoparticles and hydrophobic silica. Chem Commun (Camb) 52(15):3179-3182. https://doi.org/10.1039/c5cc09561a

11. Simonsen SB, Chorkendorff I, Dahl S, Skoglundh M, Sehested J, Helveg S (2011) Ostwald ripening in a $\mathrm{Pt} / \mathrm{SiO}_{2}$ model catalyst studied by in situ TEM. J Catal 281(1):147-155. https://doi.org/10. 1016/j.jcat.2011.04.011

12. Zhao K, Qiao B, Wang J, Zhang Y, Zhang T (2011) A highly active and sintering-resistant $\mathrm{Au} / \mathrm{FeO}_{\mathrm{x}}$-hydroxyapatite catalyst for $\mathrm{CO}$ oxidation. Chem Commun (Camb) 47(6):1779-1781. https://doi.org/ 10.1039/c0cc04171h

13. Yan W, Brown S, Pan Z, Mahurin SM, Overbury SH, Dai S (2006) Ultrastable gold nanocatalyst supported by nanosized non-oxide substrate. Angew Chem Int Ed Engl 45(22):3614-3618. https:// doi.org/10.1002/anie.200503808

14. Wang Y, B-b C, Crocker M, Y-j Z, X-b Z, Shi C (2015) Understanding on the origins of hydroxyapatite stabilized gold nanoparticles as high-efficiency catalysts for formaldehyde and benzene oxidation. Catal Commun 59:195-200. https://doi.org/ 10.1016/j.catcom.2014.10.028

15. Dick K, Dhanasekaran T, Zhang Z, Meisel D (2002) Sizedependent melting of silica-encapsulated gold nanoparticles. J Am Chem Soc 124(10):2312-2317. https://doi.org/10.1021/ ja017281a

16. Zhang Y, Zhou Y, Zhang Z, Xiang S, Sheng X, Zhou S, Wang F (2014) Synthesis and characterization of a novel Au nanocatalyst with increased thermal stability. Dalton Trans 43(3):1360-1367. https://doi.org/10.1039/c3dt52108g

17. Xiang S, Zhou Y, Zhang Y, Zhang Z, Sheng X, Zhou S, Yang Z (2014) A highly reactive and enhanced thermal stability nanocomposite catalyst based on $\mathrm{Au}$ nanoparticles assembled in the inner surface of $\mathrm{SiO}_{2}$ hollow nanotubes. Dalton Trans 43(28):11039 11047. https://doi.org/10.1039/c4dt00882k

18. Rashkeev SN, Dai S, Overbury SH (2010) Modification of $\mathrm{Au} / \mathrm{TiO}_{2}$ nanosystems by $\mathrm{SiO}_{2}$ monolayers: toward the control of the Ccatalyst activity and stability. J Phys Chem C 114(7):29963002. https://doi.org/10.1021/jp9091738

19. del Río E, Hungría AB, Tinoco M, Manzorro R, Cauqui MA, Calvino JJ, Pérez-Omil JA (2016) $\mathrm{CeO}_{2}$-modified $\mathrm{Au} / \mathrm{TiO}_{2}$ catalysts with outstanding stability under harsh $\mathrm{CO}$ oxidation conditions. Appl Catal B Environ 197:86-94. https://doi.org/10.1016/j. apcatb.2016.04.037

20. Puértolas B, Mayoral Á, Arenal R, Solsona B, Moragues A, Murcia-Mascaros S, Amorós P, Hungría AB, Taylor SH, García T (2015) High-temperature stable gold nanoparticle catalysts for application under severe conditions: the role of $\mathrm{TiO}_{2}$ nanodomains in structure and activity. ACS Catal 5(2):1078-1086. https://doi.org/ $10.1021 / \operatorname{cs} 501741 \mathrm{u}$

21. Tang H, Liu F, Wei J, Qiao B, Zhao K, Su Y, Jin C, Li L, Liu JJ, Wang J, Zhang T (2016) Ultrastable hydroxyapatite/titanium-dioxide-supported gold nanocatalyst with strong metal-support interaction for carbon monoxide oxidation. Angew Chem Int Ed Engl 55(36):10606-10611. https://doi.org/10.1002/anie.201601823

22. Barrett DH, Scurrell MS, Rodella CB, Diaz B, Billing DG, Franklyn PJ (2016) Achieving nano-gold stability through rational design. Chem Sci 7(11):6815-6823. https://doi.org/10.1039/ c6sc01597b

23. Tian C, Zhu X, Abney CW, Liu X, Foo GS, Wu Z, Li M, Meyer HM, Brown S, Mahurin SM, Wu S, Yang S-Z, Liu J, Dai S (2017) Toward the design of a hierarchical perovskite support: ultrasintering-resistant gold nanocatalysts for $\mathrm{CO}$ oxidation. ACS Catal 7(5):3388-3393. https://doi.org/10.1021/acscatal.7b00483

24. Hemmingson SL, Campbell CT (2017) Trends in adhesion energies of metal nanoparticles on oxide surfaces: understanding support effects in catalysis and nanotechnology. ACS Nano 11:11961203. https://doi.org/10.1021/acsnano.6b07502 
25. Ouyang R, Liu JX, Li WX (2013) Atomistic theory of Ostwald ripening and disintegration of supported metal particles under reaction conditions. J Am Chem Soc 135(5):1760-1771. https://doi.org/ 10.1021/ja3087054

26. Simakova IL, Solkina YS, Moroz BL, Simakova OA, Reshetnikov SI, Prosvirin IP, Bukhtiyarov VI, Parmon VN, Murzin DY (2010) Selective vapour-phase $\alpha$-pinene isomerization to camphene over gold-on-alumina catalyst. Appl Catal, A 385(1-2):136-143. https:// doi.org/10.1016/j.apcata.2010.07.002

27. Ivanova S, Petit C, Pitchon V (2006) Application of heterogeneous gold catalysis with increased durability: oxidation of $\mathrm{CO}$ and hydrocarbons at low temperature. Gold Bull 39(1):3-8. https://doi. org $/ 10.1007 / \mathrm{bf03215526}$

28. Gong J (2012) Structure and surface chemistry of gold-based model catalysts. Chem Rev 112(5):2987-3054. https://doi.org/10.1021/ cr200041p

29. Abd El-Moemen A, Abdel-Mageed AM, Bansmann J, ParlinskaWojtan M, Behm RJ, Kučerová G (2016) Deactivation of $\mathrm{Au} / \mathrm{CeO}_{2}$ catalysts during $\mathrm{CO}$ oxidation: influence of pretreatment and reaction conditions. J Catal 341:160-179. https://doi.org/10.1016/j.jcat. 2016.07.005

30. Zanella R (2004) Characterization and reactivity in CO oxidation of gold nanoparticles supported on $\mathrm{TiO}_{2}$ prepared by depositionprecipitation with $\mathrm{NaOH}$ and urea. J Catal 222(2):357-367. https://doi.org/10.1016/j.jcat.2003.11.005

31. Zanella R, Louis C (2005) Influence of the conditions of thermal treatments and of storage on the size of the gold particles in $\mathrm{Au} /$ $\mathrm{TiO}_{2}$ samples. Catal Today 107-108:768-777. https://doi.org/10. 1016/j.cattod.2005.07.008

32. Akita T, Lu P, Ichikawa S, Tanaka K, Haruta M (2001) Analytical TEM study on the dispersion of $\mathrm{Au}$ nanoparticles in $\mathrm{Au} / \mathrm{TiO}_{2}$ catalyst prepared under various temperatures. Surf Interface Anal 31(2):73-78. https://doi.org/10.1002/sia.959

33. Bore MT, Pham HN, Ward TL, Datye AK (2004) Role of pore curvature on the thermal stability of gold nanoparticles in mesoporous silica. Chem Commun (Camb) (22):2620-2621. https://doi. org $/ 10.1039 / \mathrm{b} 407575 \mathrm{~g}$

34. Yan X, Wang X, Tang Y, Ma G, Zou S, Li R, Peng X, Dai S, Fan J (2013) Unusual loading-dependent sintering-resistant properties of gold nanoparticles supported within extra-large mesopores. Chem Mater 25(9):1556-1563. https://doi.org/10.1021/cm303816g

35. Gabaldon JP, Bore M, Datye AK (2007) Mesoporous silica supports for improved thermal stability in supported Au catalysts. Top Catal 44(1-2):253-262. https://doi.org/10.1007/s11244-007-0298-4

36. Yan X, Wang X, Tang Y, Ma G, Zou S, Li R, Peng X, Dai S, Fan J (2013) Ordered, extra-large mesopores with highly loaded gold nanoparticles: a new sintering- and coking-resistant catalyst system. Chem Commun (Camb) 49(66):7274-7276. https://doi.org/10. 1039/c3cc39196e

37. Bore MT, Pham HN, Switzer EE, Ward TL, Fukuoka A, Datye AK (2005) The role of pore size and structure on the thermal stability of gold nanoparticles within mesoporous silica. J Phys Chem B 109(7):2873-2880. https://doi.org/10.1021/jp045917p

38. Liu Z, Che R, Elzatahry AA, Zhao D (2014) Direct imaging Au nanoparticle migration inside mesoporous silica channels. ACS Nano 8(10):10455-10460. https://doi.org/10.1021/nn503794v

39. Zhu H, Liang C, Yan W, Overbury SH, Dai S (2006) Preparation of highly active silica-supported $\mathrm{Au}$ catalysts for $\mathrm{CO}$ oxidation by a solution-based technique. J Phys Chem B 110(22):10842-10848. https://doi.org/10.1021/jp060637q

40. Veith GM, Lupini AR, Rashkeev S, Pennycook SJ, Mullins DR, Schwartz V, Bridges CA, Dudney NJ (2009) Thermal stability and catalytic activity of gold nanoparticles supported on silica. J Catal 262:92-101
41. Hansen TW, Delariva AT, Challa SR, Datye AK (2013) Sintering of catalytic nanoparticles: particle migration or Ostwald ripening? Acc Chem Res 46(8):1720-1730. https://doi.org/10.1021/ar3002427

42. Wynblatt P, Gjostein NA (1975) Supported metal crystallites. Prog Solid State Chem 9:21-58. https://doi.org/10.1016/0079-6786(75) 90013-8

43. Datye AK, Xu Q, Kharas KC, McCarty JM (2006) Particle size distributions in heterogeneous catalysts: what do they tell us about the sintering mechanism? Catal Today 111(1-2):59-67. https://doi. org/10.1016/j.cattod.2005.10.013

44. Munnik P, Velthoen ME, de Jongh PE, de Jong KP, Gommes CJ (2014) Nanoparticle growth in supported nickel catalysts during methanation reaction-larger is better. Angew Chem Int Ed Engl 53(36):9493-9497. https://doi.org/10.1002/anie.201404103

45. Rasmussen DB, Janssens TVW, Temel B, Bligaard T, Hinnemann B, Helveg S, Sehested J (2012) The energies of formation and mobilities of $\mathrm{Cu}$ surface species on $\mathrm{Cu}$ and $\mathrm{ZnO}$ in methanol and water gas shift atmospheres studied by DFT. J Catal 293:205-214. https://doi.org/10.1016/j.jcat.2012.07.001

46. Hugon A, Kolli NE, Louis C (2010) Advances in the preparation of supported gold catalysts: mechanism of deposition, simplification of the procedures and relevance of the elimination of chlorine. J Catal 274(2):239-250. https://doi.org/10.1016/j.jcat.2010.07.008

47. Prieto G, Zecevic J, Friedrich H, de Jong KP, de Jongh PE (2013) Towards stable catalysts by controlling collective properties of supported metal nanoparticles. Nat Mater 12(1):34-39. https://doi.org/ 10.1038/nmat3471

48. Delannoy L, El Hassan N, Musi A, Le To NN, Krafft JM, Louis C (2006) Preparation of supported gold nanoparticles by a modified incipient wetness impregnation method. J Phys Chem B 110(45): 22471-22478. https://doi.org/10.1021/jp0621301

49. Dachille F, Sruousr PY, Roy R (1968) Pressure-temperature studies of anatase, brookite, rutile and $\mathrm{TiO}_{2}$-II. Am Mineral 53:1929-1939

50. Tada K, Koga H, Hayashi A, Kondo Y, Kawakami T, Yamanaka S, Okumura M (2017) Theoretical clarification of the coexistence of $\mathrm{Cl}$ effects on $\mathrm{Au} / \mathrm{TiO} 2$ : the interaction between $\mathrm{Au}$ clusters and the $\mathrm{TiO} 2$ surface, and the aggregation of $\mathrm{Au}$ clusters on the $\mathrm{TiO} 2$ surface. Bull Chem Soc Jpn 90(5):506-519. https://doi.org/10.1246/ bcsj. 20160359

51. Farmer JA, Campbell CT (2010) Ceria maintains smaller metal catalyst particles by strong metal-support bonding. Science 329(5994):933-936. https://doi.org/10.1126/science.1191778

52. Harris PJF (2013) Growth and structure of supported metal catalyst particles. Int Mater Rev 40(3):97-115. https://doi.org/10.1179/imr. 1995.40.3.97

53. Sehested J (2003) Sintering of nickel steam-reforming catalysts. J Catal 217(2):417-426. https://doi.org/10.1016/s0021-9517(03) 00075-7

54. Campbell CT, Parker SC, Starr DE (2002) The effect of sizedependent nanoparticle energetics on catalyst sintering. Science 298(5594):811-814. https://doi.org/10.1126/science.1075094

55. Parker SC, Campbell CT (2007) Kinetic model for sintering of supported metal particles with improved size-dependent energetics and applications to $\mathrm{Au}$ onTiO 2 (110). Phys Rev B 75(3). https://doi. org/10.1103/PhysRevB.75.035430

56. Prieto G, Meeldijk JD, de Jong KP, de Jongh PE (2013) Interplay between pore size and nanoparticle spatial distribution: consequences for the stability of $\mathrm{CuZn} / \mathrm{SiO}_{2}$ methanol synthesis catalysts. J Catal 303:31-40. https://doi.org/10.1016/j.jcat.2013.02.023

57. Parkinson GS, Novotny Z, Argentero G, Schmid M, Pavelec J, Kosak R, Blaha P, Diebold U (2013) Carbon monoxide-induced adatom sintering in a $\mathrm{Pd}-\mathrm{Fe}_{3} \mathrm{O}_{4}$ model catalyst. Nat Mater 12(8): 724-728. https://doi.org/10.1038/nmat3667

58. Ono LK, Roldan Cuenya B (2008) Formation and thermal stability of $\mathrm{Au}_{2} \mathrm{O}_{3}$ on gold nanoparticles: size and support effects. J Phys Chem C 112(12):4676-4686. https://doi.org/10.1021/jp711277u 
59. Fujitani T, Nakamura I (2011) Mechanism and active sites of the oxidation of $\mathrm{CO}$ over $\mathrm{Au} / \mathrm{TiO}_{2}$. Angew Chem Int Ed Engl 50(43): 10144-10147. https://doi.org/10.1002/anie.201104694

60. Weiher N, Beesley AM, Tsapatsaris N, Delannoy L, Louis C, van Bokhoven JA, Schroeder SL (2007) Activation of oxygen by metallic gold in $\mathrm{Au} / \mathrm{TiO}_{2}$ catalysts. J Am Chem Soc 129(8):2240 2241. https://doi.org/10.1021/ja067316c

61. Kotobuki M, Leppelt R, Hansgen DA, Widmann D, Behm RJ (2009) Reactive oxygen on a $\mathrm{Au} / \mathrm{TiO}_{2}$ supported catalyst. J Catal 264(1):67-76. https://doi.org/10.1016/j.jcat.2009.03.013

62. Duan Z, Henkelman G (2015) CO oxidation at the $\mathrm{Au} / \mathrm{TiO}_{2}$ boundary: the role of the Au/Ti5c site. ACS Catal 5(3):1589-1595. https:// doi.org/10.1021/cs501610a

63. Saavedra J, Doan HA, Pursell CJ, Grabow LC, Chandler BD (2014) The critical role of water at the gold-titania interface in catalytic $\mathrm{CO}$ oxidation. Science 345(6204):1599-1602. https://doi.org/10.1126/ science. 1256018

64. Comotti M, Li WC, Spliethoff B, Schuth F (2006) Support effect in high activity gold catalysts for $\mathrm{CO}$ oxidation. J Am Chem Soc 128(3):917-924. https://doi.org/10.1021/ja0561441

65. Date M, Okumura M, Tsubota S, Haruta M (2004) Vital role of moisture in the catalytic activity of supported gold nanoparticles. Angew Chem Int Ed Engl 43(16):2129-2132. https://doi.org/10. 1002/anie.200453796
66. Haruta M (2003) When gold is not noble: catalysis by nanoparticles. Chem Rec 3(2):75-87. https://doi.org/10.1002/tcr.10053

67. Pougin A, Lüken A, Klinkhammer C, Hiltrop D, Kauer M, Tölle K, Havenith-Newen M, Morgenstern K, Grünert W, Muhler M, Strunk $\mathrm{J}$ (2017) Probing oxide reduction and phase transformations at the $\mathrm{Au}-\mathrm{TiO}_{2}$ interface by vibrational spectroscopy. Top Catal 60:17441753. https://doi.org/10.1007/s11244-017-0851-8

68. Lopez N, Norskov JK, Janssens TVW, Carlsson A, Puig-Molina A, Clausen BS, Grunwaldt JD (2004) The adhesion and shape of nanosized $\mathrm{Au}$ particles in a $\mathrm{Au} / \mathrm{TiO}_{2}$ catalyst. J Catal 225(1):8694. https://doi.org/10.1016/j.jcat.2004.03.036

69. Schubert MM, Hackenberg S, van Veen AC, Muhler M, Plzak V, Behm RJ (2001) CO oxidation over supported gold catalysts"inert" and "active" support materials and their role for the oxygen supply during reaction. J Catal 197(1):113-122. https://doi.org/10. 1006/jcat.2000.3069

70. Masoud N, Delannoy L, Schaink H, van der Eerden A, de Rijk JW, Silva TAG, Banerjee D, Meeldijk JD, de Jong KP, Louis C, de Jongh PE (2017) Superior stability of $\mathrm{Au} / \mathrm{SiO}_{2}$ compared to $\mathrm{Au} /$ $\mathrm{TiO}_{2}$ catalysts for the selective hydrogenation of butadiene. ACS Catal 7:5594-5603. https://doi.org/10.1021/acscatal.7b01424

Publisher's note Springer Nature remains neutral with regard to jurisdictional claims in published maps and institutional affiliations. 